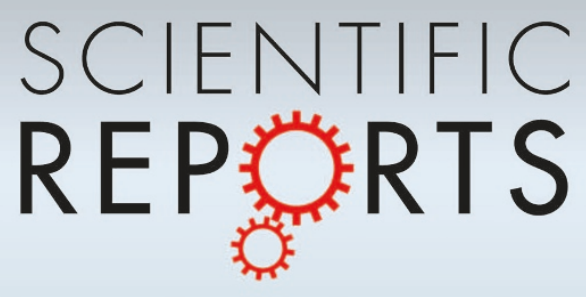

OPEN

SUBJECT AREAS:

ATMOSPHERIC

CHEMISTRY

ENVIRONMENTAL MONITORING

Received

9 April 2014

Accepted

10 September 2014

Published

30 September 2014

Correspondence and requests for materials should be addressed to H.T. (tanimoto@nies. go.jp)

\section{Emissions of methane from offshore oil and gas platforms in Southeast Asia}

\author{
Hideki Nara, Hiroshi Tanimoto, Yasunori Tohjima, Hitoshi Mukai, Yukihiro Nojiri \& Toshinobu Machida
}

Center for Global Environmental Research, National Institute for Environmental Studies, 16-2 Onogawa, Tsukuba, Ibaraki 305-8506, Japan.

Methane is a substantial contributor to climate change. It also contributes to maintaining the background levels of tropospheric ozone. Among a variety of $\mathrm{CH}_{4}$ sources, current estimates suggest that $\mathrm{CH}_{4}$ emissions from oil and gas processes account for approximately $20 \%$ of worldwide anthropogenic emissions. Here, we report on observational evidence of $\mathrm{CH}_{4}$ emissions from offshore oil and gas platforms in Southeast Asia, detected by a highly time-resolved spectroscopic monitoring technique deployed onboard cargo ships of opportunity. We often encountered $\mathrm{CH}_{4}$ plumes originating from operational flaring/venting and fugitive emissions off the coast of the Malay Peninsula and Borneo. Using night-light imagery from satellites, we discovered more offshore platforms in this region than are accounted for in the emission inventory. Our results demonstrate that current knowledge regarding $\mathrm{CH}_{4}$ emissions from offshore platforms in Southeast Asia has considerable uncertainty and therefore, emission inventories used for modeling and assessment need to be re-examined.

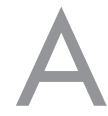

tmospheric $\mathrm{CH}_{4}$ is an important component of short-lived climate pollutants that contribute both directly and indirectly to radiative forcing. It is also known that $\mathrm{CH}_{4}$ contributes to maintaining the background levels of tropospheric ozone ${ }^{1} . \mathrm{CH}_{4}$ is emitted from a variety of natural (e.g., wetlands, oceans, termites, and clathrates) and anthropogenic (e.g., fossil-fuel exploitation, ruminant animals, rice cultivation, waste management, and biomass burning) sources. Because of the shorter atmospheric lifetime (about nine years ${ }^{2}$ ) of $\mathrm{CH}_{4}$ than $\mathrm{CO}_{2}$, a reduction of anthropogenic emissions of $\mathrm{CH}_{4}$ would be an effective means of abating global warming in the near future ${ }^{3,4}$. However, to establish strategies for the mitigation of global warming, a quantitative understanding of the global $\mathrm{CH}_{4}$ budget is required.

Atmospheric abundance of $\mathrm{CH}_{4}$ has been increasing from pre-industrial levels of about $700 \mathrm{nmol} \mathrm{mol}{ }^{-1}$ (hereafter referred to as $\mathrm{ppb}$ ) with large year-to-year fluctuations in its growth rate ${ }^{5}$. Among the many studies that have investigated the distribution and temporal variation of $\mathrm{CH}_{4}$, several have reported conflicting results ${ }^{6-9}$. Some recent studies have suggested the existence of previously unrecognized sources of $\mathrm{CH}_{4}$. For example, satellite observations have been combined with inverse modeling techniques using $\mathrm{CH}_{4}$ retrievals from the Scanning Imaging Absorption Spectrometer for Atmospheric Chartography (SCIAMACHY) to provide a global distribution map of $\mathrm{CH}_{4}$ that suggests there are many emission hot spots in areas where surface observations are scarce ${ }^{10}$. The first airborne in situ measurements of $\mathrm{CH}_{4}$ over the Amazon region during the BARCA (Balanço Atmosphérico Regional de Carbono na Amazônia) campaign revealed strong $\mathrm{CH}_{4}$ emissions from the Amazonian wetlands ${ }^{11}$. Regular aircraft observations from the CARIBIC (Civil Aircraft for the Regular Investigation of the atmosphere Based on an Instrument Container) program suggest strong biogenic emissions from India that cannot be attributed solely to rice cultivation ${ }^{12}$. These studies show that our current understanding regarding the sources of $\mathrm{CH}_{4}$ emissions is inadequate and that greater effort is needed to obtain better knowledge both of the strength of $\mathrm{CH}_{4}$ emissions and of the distribution of the sources. For this purpose, a more systematic approach is required regarding the acquisition of $\mathrm{CH}_{4}$ observations in areas where observational data are sporadic or sparse.

Since 1992, the National Institute for Environmental Studies (NIES) has conducted a voluntary observing ships (VOS) program of long-term atmospheric monitoring of climatically important trace gases over the Pacific Ocean ${ }^{13,14}$. In the Southeast Asian region, atmospheric monitoring as part of the NIES-VOS program commenced in September 2007. Although flask sampling was initially used for $\mathrm{CH}_{4}$ monitoring, since 2009, the program has been augmented by the use of continuous measurements that capture the highly variable features of $\mathrm{CH}_{4}$ in the regionally polluted air in Southeast Asia. In this paper, we present the first results of the high-resolution continuous onboard measurements of $\mathrm{CH}_{4}$ in the marine boundary layer (MBL) in the Southeast Asian region between September 2009 and April 2012. We focus on the $\mathrm{CH}_{4}$ distribution in the northern equatorial region, 

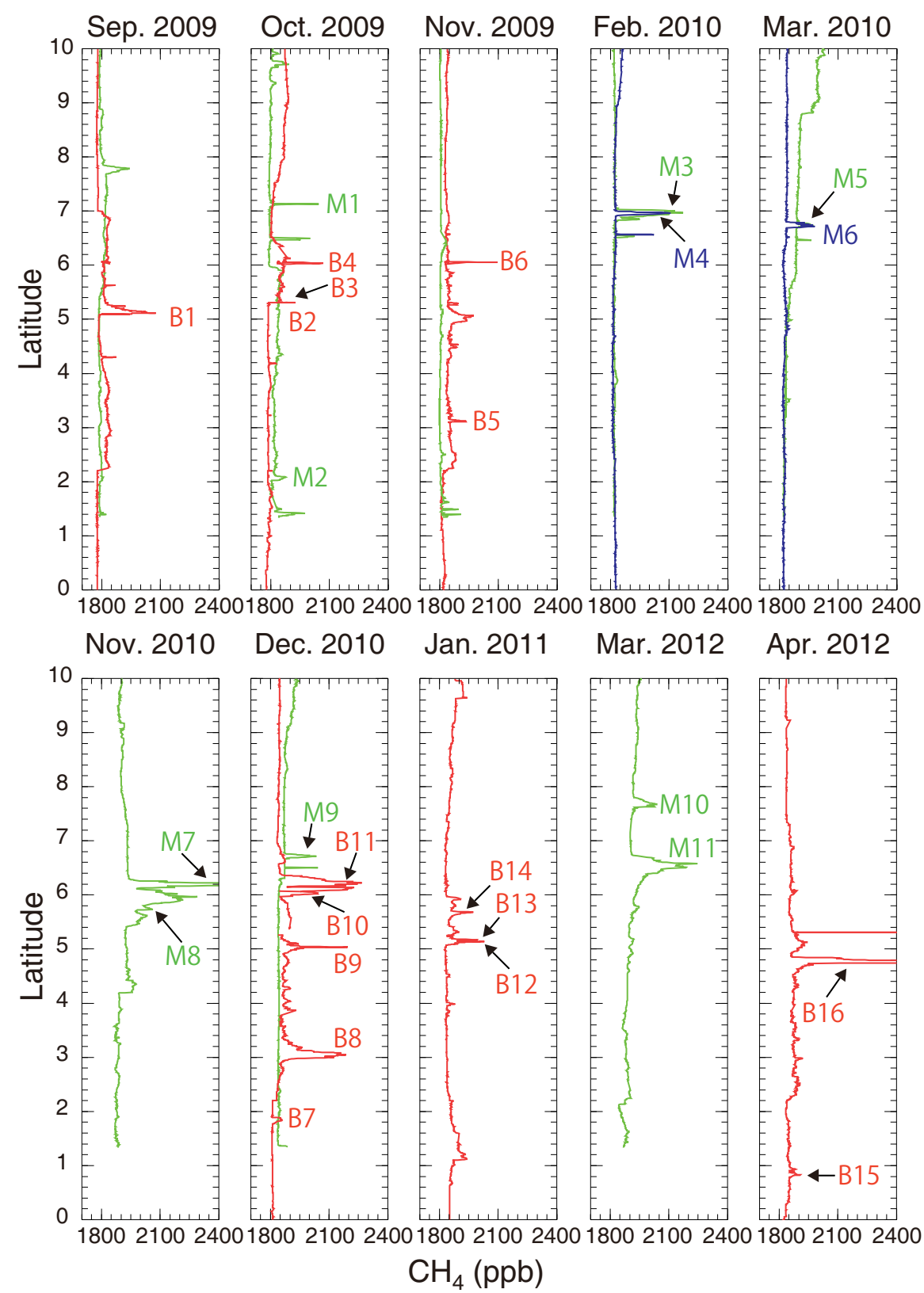

Figure $1 \mid$ Latitudinal distribution of 1-min temporally averaged $\mathrm{CH}_{4}$ mole fractions between latitude $10^{\circ} \mathrm{N}$ and the equator observed during eight voyages along the Southeast Asian shipping routes between September 2009 and April 2012. Mole fractions of $\mathrm{CH}_{4}$ are $\mathrm{color} \mathrm{coded}$ according to the shipping routes: green for the southbound Asia route, blue for northbound Asia route, and red for northbound Borneo route. Peak numbers are allocated for only the Malay and Borneo peaks (preceded by $\mathrm{M}$ or B) that showed substantial $\mathrm{CH}_{4}$ increase ( $>50$ ppb) and positive correlation between $\mathrm{CH}_{4}$ and $\mathrm{CO}_{2}(R>0.4$, p-value $<0.05)$ and that had peak durations of more than $10 \mathrm{~min}$.

where strong $\mathrm{CH}_{4}$ peaks were observed off the east coast of the Malay Peninsula and the northwest coast of Borneo, and we examine the emission sources responsible for these observed $\mathrm{CH}_{4}$ peaks.

\section{Results}

Although shipping operations were disrupted temporarily by the global financial crisis and the 2011 Great East Japan Earthquake, we were able to undertake observations during eight voyages between

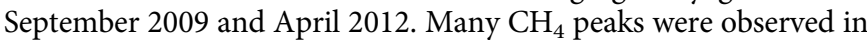
the northern equatorial region along Southeast Asian routes (Figure 1); see Methods section for further details. The locations at which these peaks occurred were concentrated in two areas: off the east coast of the Malay Peninsula (39 peaks) and off the northwest coast of Borneo ( 55 peaks); they are referred to hereafter as the Malay and Borneo peaks, respectively. The Malay peaks were observed largely between latitudes $8^{\circ} \mathrm{N}$ and $5.5^{\circ} \mathrm{N}$ along both the northbound and southbound routes, while the Borneo peaks were observed between latitudes $6.5^{\circ} \mathrm{N}$ and $4.5^{\circ} \mathrm{N}$ along the northbound Borneo route. Although the durations of all observed $\mathrm{CH}_{4}$ peaks were short, between several minutes to one hour, the increases of the mole fraction of $\mathrm{CH}_{4}$ were considerable, i.e., up to about $1100 \mathrm{ppb}$ above the baseline levels for the Southeast Asian region. Concurrent with the $\mathrm{CH}_{4}$ peaks, we observed simultaneous $\mathrm{CO}_{2}$ peaks, and the positive correlation between these $\mathrm{CO}_{2}$ and $\mathrm{CH}_{4}$ mole fractions suggested a common local, non-biogenic emission source for these gases.

To identify sources of $\mathrm{CH}_{4}$ emission, we examined satelliteobserved night-light data from the US Air Force Defense Meteorological Satellite Project Operational Linescan System (DMSP/OLS), 


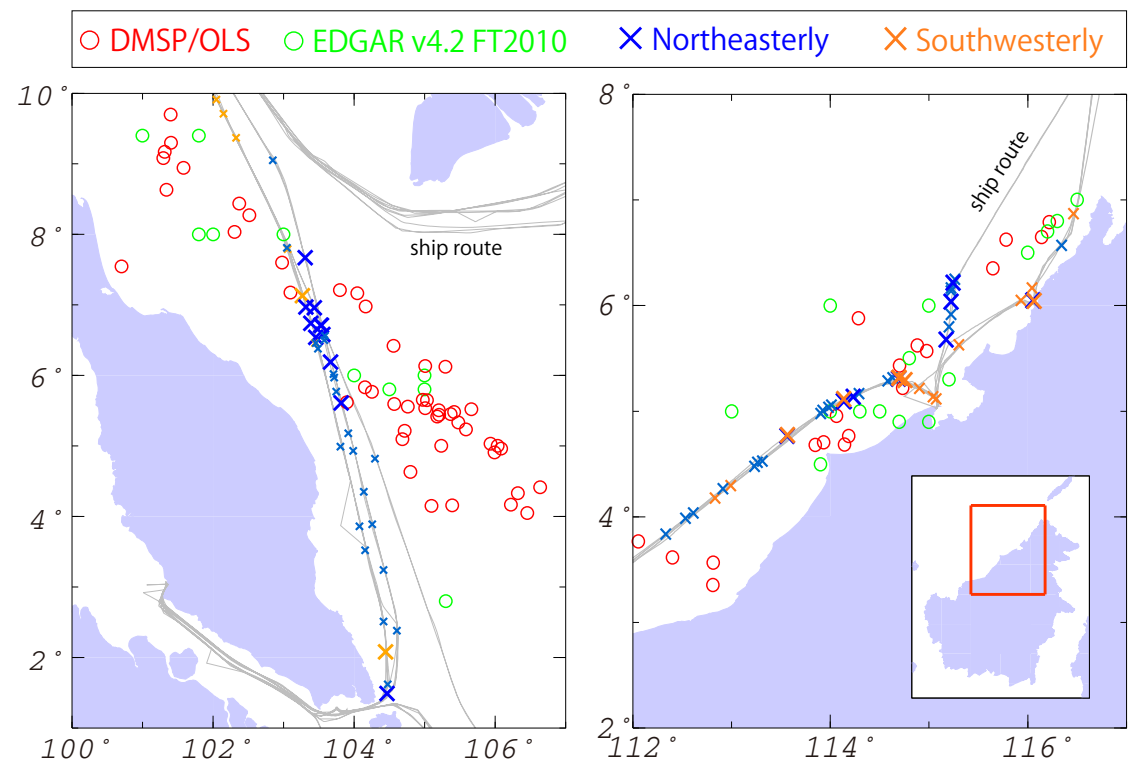

Figure $2 \mid$ Distribution of $\mathrm{CH}_{4}$ peaks observed during this study and offshore platforms off the east coast of the Malay Peninsula (left) and the northwest coast of Borneo (right). Crosses are the locations where $\mathrm{CH}_{4}$ peaks were observed and their colors explain wind patterns when each $\mathrm{CH}_{4}$ peak was observed (blue: northeasterly wind; orange: southwesterly wind). Numbered peaks in Figure 1 are emphasized as large crosses, while other marginal peaks are shown by small crosses. Open red and green circles are the locations of offshore platforms in 2010, identified based on DMSP/OLS data and as reported in the EDGAR v.4.2 FT2010 database, respectively. Gray solid lines mark the routes of the VOS ships. The maps used in this figure were generated by Generic Mapping Tools (https://www.soest.hawaii.edu/gmt/).

provided by the US National Oceanic and Atmosphere Administration ${ }^{15}$. Using the nighttime lights data "avg lights x pct", which are annual composite images of noise-filtered nighttime lights data used to infer gas-flaring volumes ${ }^{16}$, we identified the locations of offshore platforms within the study area. The distribution of these identified offshore platforms remained largely unchanged throughout our study period. Most of these platforms were either off the east coast of the Malay Peninsula or off the northwest coast of Borneo and were near the locations of the $\mathrm{CH}_{4}$ peaks along the Southeast Asian trade routes (Figure 2). Generally, $\mathrm{CH}_{4}$ is a dominant component of emissions from offshore oil platforms, released as a result of gas flaring and venting, equipment leaks, and evaporation losses, with concomitant emissions of $\mathrm{CO}_{2}$ mainly due to gas flaring ${ }^{16,17}$. These results suggest that the observed $\mathrm{CH}_{4}$ peaks represent emissions from offshore production platforms.

The $\mathrm{CH}_{4}$ emissions from offshore platforms are reported in the anthropogenic trace gas emission inventory database EDGAR (Emission Database for Global Atmospheric Research) v.4.2 FT2010 ${ }^{18}$. We compared the distribution of offshore platforms identified in this study to that reported in EDGAR. For the comparison, we used the annual composite image for 2010 from the DMSP/OLS data and annual $\mathrm{CH}_{4}$ emission data for 2010 from EDGAR. This revealed considerable discrepancy in the distribution of offshore platforms, especially off the east coast of the Malay Peninsula, which indicates that the current emission inventories of offshore platforms in Southeast Asia still include considerable uncertainties regarding $\mathrm{CH}_{4}$ and other co-emitted gas components.

Most of our observations were performed during the boreal fall and winter season when strong northeasterly winds associated with the East Asian monsoon prevail off the east coast of the Malay Peninsula; westerly winds passing over the Malay Peninsula from the Indian Ocean prevailed only during September and October of 2009 during our observations. In contrast, there was no prevailing wind direction off the northwest coastal region of Borneo during our study period. Thus, the Malay peaks observed during the northeasterly wind season should represent emissions from offshore platforms windward of the peak locations, whereas the Borneo peaks represent emissions from both offshore platforms and onshore coastal sources. To characterize the offshore platform emissions, we examined the emissions measured during the $\mathrm{CH}_{4}$ peaks based on the $\mathrm{CH}_{4}-\mathrm{CO}_{2}$ enhancement ratio $\left(\Delta \mathrm{CH}_{4} / \Delta \mathrm{CO}_{2}\right)$, which is the linear slope of the correlation of the mole fractions of $\mathrm{CH}_{4}$ and $\mathrm{CO}_{2}$. The observed enhancement ratio can often be used to identify the emission sources because it can be approximated to the emission ratio when observations are performed near the emission sources. For example, past observations at remote sites during wintertime have shown the $\Delta \mathrm{CH}_{4} / \Delta \mathrm{CO}_{2}$ ratios are typically less than about $20 \mathrm{ppb} / \mathrm{ppm}(\mathrm{ppm}$ is defined as $\mu \mathrm{mol} \mathrm{mol}^{-1}$ ) in air masses polluted principally by anthropogenic combustion-related emissions in urban and industrialized areas ${ }^{19-22}$. The emission factors of $\mathrm{CO}_{2}$ and $\mathrm{CH}_{4}$ from biomass-burning sources were determined the typical $\mathrm{CH}_{4} / \mathrm{CO}_{2}$ ratios to be less than $20 \mathrm{ppb} / \mathrm{ppm}^{23}$. These results provide diagnostic criteria for estimating the contributions from these anthropogenic emissions on land.

For further analysis of the $\Delta \mathrm{CH}_{4} / \Delta \mathrm{CO}_{2}$ ratios observed here, we selected 11 distinct Malay peaks and 16 Borneo peaks that showed substantial $\mathrm{CH}_{4}$ increases $(>50 \mathrm{ppb})$ for more than $10 \mathrm{~min}$ and significant positive correlations between $\mathrm{CH}_{4}$ and $\mathrm{CO}_{2}(R>0.4$, p-value $<0.05)$. The $\Delta \mathrm{CH}_{4} / \Delta \mathrm{CO}_{2}$ ratios during these peaks, calculated by reduced major-axis regression ${ }^{24}$, ranged from 8 to $1108 \mathrm{ppb} /$ $\mathrm{ppm}$ and from 3 to $880 \mathrm{ppb} / \mathrm{ppm}$ for the Malay and Borneo peaks, respectively (Figure 3). The M1, M3, M4, M5, M6, M8, and M9 peaks show similar $\Delta \mathrm{CO}_{2}$-vs. $-\Delta \mathrm{CH}_{4}$ correlative behavior, suggesting that they originated from the same emission process at the offshore platforms. We examined the approximate flaring efficiency (i.e., $\Delta \mathrm{CO}_{2} /$ $\left(\Delta \mathrm{CO}_{2}+\Delta \mathrm{CH}_{4}\right)$ in \%) using the $\Delta \mathrm{CO}_{2}$-vs.- $\left(\Delta \mathrm{CO}_{2}+\Delta \mathrm{CH}_{4}\right)$ regression for these peaks. The mean $\Delta \mathrm{CH}_{4} / \Delta \mathrm{CO}_{2}$ ratio for these peaks is $94 \mathrm{ppb} / \mathrm{ppm}$, corresponding to a flaring efficiency of $92 \%$. As gasflaring efficiencies for industrial flares are usually greater than $90 \%$, it is considered that these plumes originated principally from flaring with the contribution from fugitive emissions (inclusive of venting), if any, being relatively small. The M7, M10, and M11 peaks show higher $\Delta \mathrm{CH}_{4} / \Delta \mathrm{CO}_{2}$ ratios than those of the gas-flaring plumes, suggesting greater contribution from fugitive emissions. These results 

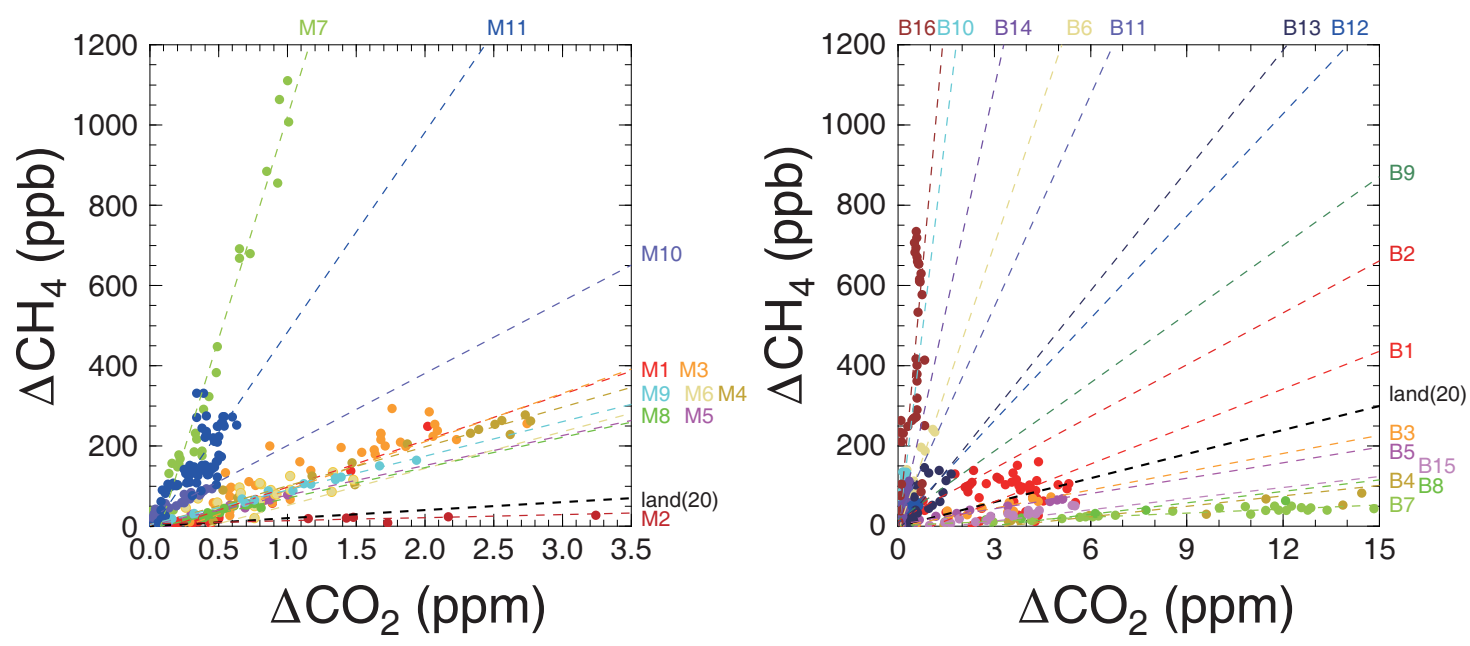

Figure 3 Scatter plots of $\mathrm{CH}_{4}$ versus $\mathrm{CO}_{2}$ mole fractions during observed $\mathrm{CH}_{4}$ peaks. Numbering of peaks is as described in Figure 1 . The left and right panels are for the Malay and Borneo peaks, respectively. Dashed lines indicate regression lines for individual peaks determined by reduced major-axis regression. The black dashed line labeled "land(20)" indicates the upper limit of the $\mathrm{CH}_{4}-\mathrm{CO}_{2}$ emission ratio for onshore anthropogenic emissions.

indicate that the observed $\Delta \mathrm{CH}_{4} / \Delta \mathrm{CO}_{2}$ ratios can vary widely, depending on the contributions from fugitive emissions. In contrast, the contributions from flaring and fugitive emissions to the M2 peak, associated with the $\Delta \mathrm{CH}_{4} / \Delta \mathrm{CO}_{2}$ ratio of $8 \mathrm{ppb} / \mathrm{ppm}$, appear negligible. Similarly, the 16 peaks observed in the Borneo area with $\Delta \mathrm{CH}_{4} / \Delta \mathrm{CO}_{2}$ ratios higher than $20 \mathrm{ppb} / \mathrm{ppm}$ were explained by the mixing of flaring and fugitive emissions. Consequently, we chose those peaks with $\Delta \mathrm{CH}_{4} / \Delta \mathrm{CO}_{2}$ ratios higher than $20 \mathrm{ppb} / \mathrm{ppm}$ for further analysis.

\section{Discussion}

We used these observed $\mathrm{CH}_{4}$ peaks to estimate the $\mathrm{CH}_{4}$ emission rates based on a mass balance approach ${ }^{25-27}$. Assuming that the $\mathrm{CH}_{4}$ plume was formed steadily during the observation and that the $\mathrm{CH}_{4}$ mixing ratio was vertically well mixed in the MBL, the $\mathrm{CH}_{4}$ emission rate $q_{\mathrm{CH} 4}$ can be expressed by:

$$
q_{C H_{4}}=u \bullet \cos \alpha \bullet n \bullet Z_{M B L} \bullet \int_{a}^{b}\left[f_{C_{4}}(y)-C_{0}(y)\right] d y
$$

In equation ( 1 ), $u$ is the mean horizontal wind speed along the plume axis, $\alpha$ is the angle between the ship transect and the perpendicular to the plume axis, $Z_{M B L}$ is the depth of the MBL, $n$ is the average molar density of air within the MBL, $y$ is the distance from the plume axis, $f_{\mathrm{CH} 4}(y)$ is the observed $\mathrm{CH}_{4}$ mole fraction at $y$, and $C_{0}(y)$ is the background $\mathrm{CH}_{4}$ mole fraction at $y$. The start and end points of the integration interval for the individual $\mathrm{CH}_{4}$ peaks, $a$ and $b$ in equation (1), are determined manually by visual inspection, and the values of $C_{0}(y)$ are determined practically by linear interpolation between the $\mathrm{CH}_{4}$ mole fractions at points $a$ and $b$. As no meteorological observations were performed onboard, the mean wind speeds and directions and the depths of the MBL were estimated based on the CGER/METEX three-dimensional kinematic trajectory model ${ }^{28}$. This trajectory model was driven by six-hourly meteorological input data from the NCEP/NCAR reanalysis, which has a spatial resolution of $2.5^{\circ} \times 2.5^{\circ}$. The model calculation was initiated at an altitude of $250 \mathrm{~m}$ above sea level at the locations of the $\mathrm{CH}_{4}$ peaks. For every plume calculation, we adopted the molar density of air $(n)$ of $1.2 \mathrm{~kg}$ $\mathrm{m}^{-3}$, which was the average value of $n$ at 0 and $0.5 \mathrm{~km}^{29}$. We applied the mass balance approach to the appropriate 14 peaks that the ship transited straight across the $\mathrm{CH}_{4}$ peak. Geographical relationships between the observed $\mathrm{CH}_{4}$ peaks and the offshore platforms were well explained by the trajectory model. The resultant $\mathrm{CH}_{4}$ emission rates for the eight Malay platform peaks: M1, M3, M4, M5, M6, M7, M8, and M9 are within the range of 3.9-426.7 $\mathrm{g} \mathrm{s}^{-1}$ with a median (mean) of $99.2(124.7) \mathrm{g} \mathrm{s}^{-1}$. The rates for the six Borneo platform peaks: $\mathrm{B} 1, \mathrm{~B} 6, \mathrm{~B} 11, \mathrm{~B} 12, \mathrm{~B} 13$, and $\mathrm{B} 14$ are within the range of 1.8$46.0 \mathrm{~g} \mathrm{~s}^{-1}$ with a median (mean) of $14.7(16.9) \mathrm{g} \mathrm{s}^{-1}$, as summarized in Table 1, together with the values of the parameters used in the calculations. These estimates are comparable with the recent preliminary estimates using the Visible Infrared Imaging Radiometer Suite on board the Suomi National Polar-orbiting Partnership satellite, provided by the National Geophysical Data Center of the National Oceanic and Atmospheric Administration ${ }^{30}$. As conservative error estimates, we evaluated uncertainty ranges for the emission rates by assuming the relative uncertainty of $\pm 50 \%$ for the two dominant factors $\left(\mathrm{u} \times \cos \theta\right.$ and $\left.\mathrm{Z}_{\mathrm{MBL}}\right)$, and $\pm 0.05 \mathrm{~kg} \mathrm{~m}^{-3}$ for the molar density of air $\left(1.2 \mathrm{~kg} \mathrm{~m}^{-3}\right)$. The calculated uncertainty ranges (from lower to upper limits), also listed in Table 1, suggest substantial uncertainty in this approach.

The median value of all the $\mathrm{CH}_{4}$ emission rates is $29.2 \mathrm{~g} \mathrm{~s}^{-1}$. Using the DMSP satellite, we identified 112 offshore platforms in the Southeast Asian region (defined as: $15^{\circ} \mathrm{N}-10^{\circ} \mathrm{S}, 90^{\circ}-140^{\circ} \mathrm{E}$ ); thus, the resultant regional total emission rate is calculated as $3.3 \mathrm{~kg} \mathrm{~s}^{-1}$. The total regional annual emission of $\mathrm{CH}_{4}$ from offshore platforms in the Southeast Asian region is estimated to be about $0.1 \mathrm{Tg}^{-1}$, associated with an uncertainty range of $0.02-0.32 \mathrm{Tg}^{-1}$ (the median values of the lower and upper limits). EDGAR reports that annual $\mathrm{CH}_{4}$ emissions from oil and gas production in 12 Southeast Asian countries (Brunei, Cambodia, Lao, Myanmar, Malaysia, the Philippines, Singapore, Thailand, Timor, Vietnam, Indonesia, and Papua New Guinea) were about $3.7 \mathrm{Tg} \mathrm{y}^{-1}$ for 2010, which corresponds to about $1 \%$ of the $335 \mathrm{Tg} \mathrm{y}^{-1}$ global anthropogenic $\mathrm{CH}_{4}$ emissions ${ }^{18}$. Offshore $\mathrm{CH}_{4}$ emissions account for about $8 \%$ $\left(0.29 \mathrm{Tg}^{-1}\right)$ of the total emissions from oil and gas production in the Southeast Asian region. Despite the large uncertainty inherent in the mass balance approach, our estimate displays relatively good agreement with that by EDGAR. However, we note substantial differences in the locations of the offshore platforms between the EDGAR inventory and those determined by DMSP satellite observation. The distributions of point sources of $\mathrm{CH}_{4}$ are an important uncertainty in the existing inventories. The relative contributions of the offshore $\mathrm{CH}_{4}$ emissions to the regional $\mathrm{CH}_{4}$ emissions in Southeast Asia are estimated to be about 3\% for the oil and gas production sector (both offshore and onshore) $\left(3.7 \mathrm{Tg}^{-1}\right.$, as esti- 
Table 1 | Estimated $\mathrm{CH}_{4}$ emission rates for the observed $\mathrm{CH}_{4}$ peaks

\begin{tabular}{|c|c|c|c|c|c|c|}
\hline Area & Peak No. & $u\left(\mathrm{~m} \mathrm{~s}^{-1}\right)$ & $\alpha$ (deg.) & $\mathrm{Z}_{\mathrm{MBL}}(\mathrm{m})$ & $\int_{a}^{b}\left[f_{C_{H}}(y)-C_{0}(y)\right] d y\left(\mathrm{ppm} \mathrm{m} \times 10^{4}\right)$ & $q_{\mathrm{CH}_{4}}\left(\mathrm{~g} \mathrm{~s}^{-1}\right)$ \\
\hline \multirow[t]{5}{*}{ Malay } & Ml & 2.4 & 38.0 & 565 & 1.4 & $38.1(9.1-89.3)$ \\
\hline & M3 & 2.8 & 2.1 & 252 & 10.0 & $180.8(43.3-423.8)$ \\
\hline & M5 & 5.1 & 12.2 & 556 & 0.23 & $16.8(4.0-39.4)$ \\
\hline & M6 & 5.8 & 25.4 & 505 & 1.6 & $110.7(26.5-259.5)$ \\
\hline & M7 & 2.1 & 46.5 & 574 & 20.2 & $426.7(102.2-1000.0)$ \\
\hline \multirow[t]{6}{*}{ Borneo } & B1 & 3.6 & 82.1 & 517 & 7.0 & $46.0(11.0-107.9)$ \\
\hline & B6 & 3.4 & 9.9 & 469 & 0.43 & $17.5(4.2-41.1)$ \\
\hline & B11 & 0.8 & 11.7 & 651 & 0.31 & $4.0(1.0-9.3)$ \\
\hline & $\mathrm{B} 12$ & 3.9 & 78.9 & 597 & 0.16 & $1.8(0.4-4.3)$ \\
\hline & $\mathrm{B} 13$ & 3.9 & 78.0 & 588 & 1.6 & $20.2(4.9-47.5)$ \\
\hline & $\mathrm{B} 14$ & 3.0 & 78.9 & 674 & 1.2 & $11.8(2.8-27.6)$ \\
\hline
\end{tabular}

The value of $1.2 \mathrm{~kg} \mathrm{~m}^{-3}$ is used for the molar density of air to calculate the $\mathrm{CH}_{4}$ emission rates. Figures in parentheses are the uncertainty ranges.

mated by EDGAR), and about $0.2 \%$ for the anthropogenic sources (63 $\mathrm{Tg} \mathrm{y}^{-1}$, as estimated by EDGAR).

The global $\mathrm{CH}_{4}$ emissions in 2011 are estimated to be $556 \pm 56 \mathrm{Tg}$ $\mathrm{y}^{-1}$, with contributions from natural and anthropogenic emissions being comparable ${ }^{31}$. Natural emissions from wetlands are the single most dominant contributor to the total $\mathrm{CH}_{4}$ emissions, with the annual emissions being approximately $200 \mathrm{Tg} \mathrm{y}^{-1}$. The middle-class sources with the annual emissions in the range of $10-100 \mathrm{Tg} \mathrm{y}^{-1}$ include fossil fuels, ruminants, landfills/waste, geological sources, freshwater, rice paddies, burning of biomass/biofuels, wild animals, and termites. The emissions from other sources are minor. The emissions (and range) from hydrates, wildfires, and permafrost are estimated to be 6 (2-9), $3(1-5)$, and $1(0-1) \mathrm{Tg} \mathrm{y}^{-1}$, respectively.

Globally, there are a number of offshore fields for oil and gas production. In addition to Southeast Asia, the North Sea, Persian Gulf, Gulf of Guinea, and Gulf of Mexico are known to be active in oil and gas production. As noted above, our estimate and EDGAR are in relatively good agreement for offshore $\mathrm{CH}_{4}$ emissions in Southeast Asia. A simple global estimate based on EDGAR implies that $\mathrm{CH}_{4}$ emissions from worldwide offshore oil and gas platforms are 1-2 Tg $\mathrm{y}^{-1}$, suggesting that the emissions from offshore sources may be comparable to those from minor natural sources such as wildfires and permafrost.

To our knowledge, this work marks the first top-down constraint on $\mathrm{CH}_{4}$ emissions from oil and gas platforms in Southeast Asia. On the other hand, we also realize the considerable uncertainty in our estimates, which derive from a combination of features inherent in the mass balance approach and the lack of samples of $\mathrm{CH}_{4}$ plumes from offshore platforms, due to the sporadic occurrence of gas flaring and fugitive emissions at oil and gas platforms. Hence, our top-down estimates of $\mathrm{CH}_{4}$ emissions from offshore platforms located in the Southeast Asian region need to be tested and improved. For example, if fugitive plumes were undersampled in our observations, the estimated $\mathrm{CH}_{4}$ emissions would be much greater, possibly even by one order of magnitude. To better assess the regional total emissions of $\mathrm{CH}_{4}$ from offshore platforms and thereby improve the current emissions inventory, further top-down constraints by integrated ship, aircraft, and satellite observations are needed. In particular, the detection of fugitive plumes would be useful to reduce uncertainties in estimating the emissions. Current estimates of $\mathrm{CH}_{4}$ emissions from oil and gas processes were approximately $20 \%$ of worldwide anthropogenic emissions in 2010, and they are expected to increase by nearly $35 \%$ between 2010 and $2020^{32}$. The feedback gained from plume observations can help in the reduction of fugitive emissions in
Southeast Asian countries and thus, contribute to the mitigation of global warming.

\section{Methods}

We used two commercial cargo vessels in the VOS program in Southeast Asia: the M/ V Fujitrans World (owned by the Kagoshima Senpaku Kaisya, Ltd., Japan) was the primary vessel with backup provided by the M/V Trans Future 1 (owned by the Toyofuji Shipping Co. Ltd., Japan). These ships regularly sail the trade routes between Japan and Southeast Asia, berthing at Osaka, Yokohama, and Nagoya (Japan); Hong Kong (China); Laem Chabang (Thailand); Singapore; Port Klang, Kuching and Kota Kinabalu (Malaysia); Jakarta (Indonesia); and Muara (Brunei) at four-week intervals (Figure 4). Two northbound routes are used from Jakarta to Japan: one via Thailand and the Philippines (the northbound Asia route) and the other via Borneo (the northbound Borneo route). Only one southbound route is used from Japan to Indonesia.

Onboard each VOS ship, continuous measurements of $\mathrm{CO}_{2}, \mathrm{CO}$, and $\mathrm{O}_{3}$ were performed using a non-dispersive infrared analyzer (NDIR), an NDIR with gas filter correlation, and an ultraviolet absorption analyzer, respectively. The continuous $\mathrm{CO}_{2}$ data processed for public use are available at our webpage (http://soop.jp/). Flask samples were also collected for laboratory analysis of $\mathrm{CO}_{2}, \mathrm{CO}, \mathrm{CH}_{4}, \mathrm{~N}_{2} \mathrm{O}, \mathrm{SF}_{6}, \mathrm{H}_{2}$,

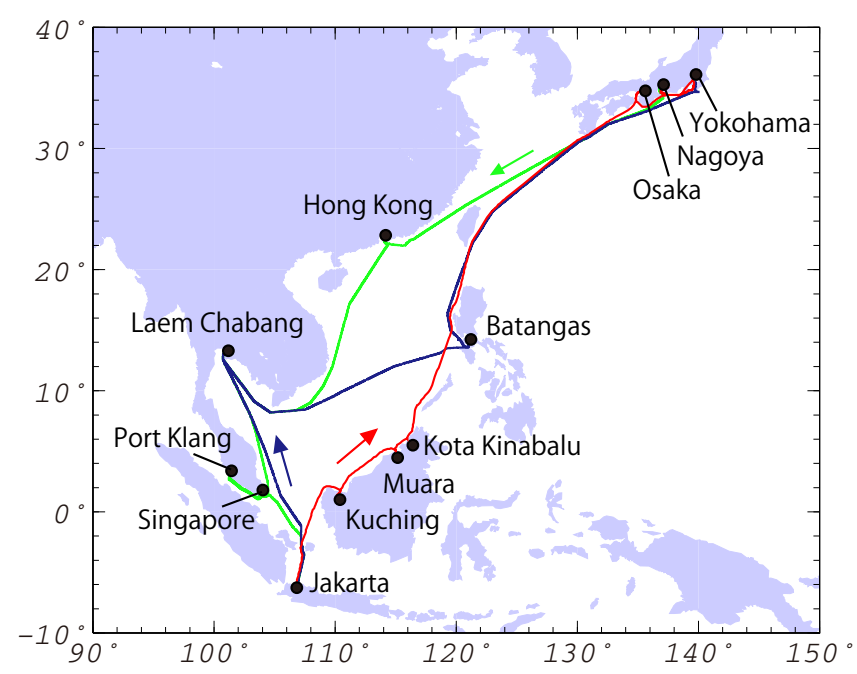

Figure 4 | The VOS shipping routes in Southeast Asia. Green and blue lines show the southbound (Japan-Indonesia) and northbound (Indonesia-Japan) Asia routes respectively; a red line shows the northbound Borneo route (Indonesia-Japan). Regular berthing ports are shown as solid black circles. The maps used in this figure were generated by Generic Mapping Tools (https://www.soest.hawaii.edu/gmt/). 
$\mathrm{O}_{2} / \mathrm{N}_{2}$, and $\mathrm{CO}_{2}$ isotopologues $\left({ }^{13} \mathrm{CO}_{2},{ }^{12} \mathrm{C}^{18} \mathrm{O}^{16} \mathrm{O}\right)$. A detailed description of the atmospheric observation system is provided elsewhere ${ }^{13}$.

In September 2009, continuous measurements of atmospheric $\mathrm{CO}_{2}$ and $\mathrm{CH}_{4}$ were commenced on VOS ships along both of the Southeast Asian routes using wavelength-scanned cavity ring-down spectroscopy (WS-CRDS) instruments (Picarro Inc., Santa Clara, CA, USA, models EnviroSense 3000i and G1301). Air sample was collected from the air intake set at the top deck of the ship (approximately $50 \mathrm{~m}$ above sea level) using a diaphragm pump placed in the observation room. The sampled air was dried before analysis to minimize biases due to dilution and pressure-broadening effects of water vapor on the WS-CRDS measurements. The sampled air was dehumidified by passing it through a sample-drying unit consisting of an electric cooler kept at $+1^{\circ} \mathrm{C}$ and a Nafion Perma Pure dryer (Perma Pure LLC, Toms River, NJ, USA). The design and performance of the unit was very similar to that used for the $\mathrm{CO}$ measurements ${ }^{13}$. The sampled air was dried to less than $\sim 0.3 \%$ water (as measured by the WS-CRDS) before the mole fractions of $\mathrm{CO}_{2}$ and $\mathrm{CH}_{4}$ were determined based on the water vapor content according to an instrument-specific water vapor collection function ${ }^{33}$. To our experience, the air samples were rarely contaminated with the ship's exhaust, when the ship sails at approximately 20 knot because the ship's exhaust is located at stern side. When the air samples were contaminated with the exhaust gas, we judged it by the $\mathrm{CO}_{2}$ and $\mathrm{O}_{3}$ measurements $\left(\mathrm{CO}_{2}\right.$ increase and $\mathrm{O}_{3}$ decrease), and then rejected the data before the analysis.

For instrument calibration, we prepared a set of three natural or purified airbalanced standard gases with $\mathrm{CO}_{2}$ and $\mathrm{CH}_{4}$ (ca. 380, 400, and $420 \mathrm{ppm}$ for $\mathrm{CO}_{2}$, and 1800,2000 , and $2200 \mathrm{ppb}$ for $\mathrm{CH}_{4}$ ) in our laboratory to prevent pressure-broadening effects due to the different air compositions of the samples and standard gases. The standard gases were introduced into the WS-CRDS instrument daily in series, $10 \mathrm{~min}$ for each gas. The mole fractions of $\mathrm{CO}_{2}$ and $\mathrm{CH}_{4}$ in the standard gases were calibrated against NIES standard gas scales (NIES 09 for $\mathrm{CO}_{2}$, NIES 96 for $\mathrm{CH}_{4}$ ), which are traceable to World Meteorological Organization standard gas scales. The analytical precision for 1-min measurements by the WS-CRDS instruments of $\mathrm{CO}_{2}$ and $\mathrm{CH}_{4}$ were typically $0.05 \mathrm{ppm}$ and $0.5 \mathrm{ppb}$ ( 1 sigma), respectively. In this study, we used only the 1-min temporal mean $\mathrm{CH}_{4}$ and $\mathrm{CO}_{2}$ data from the continuous measurements because of the coarse resolution of the $\mathrm{CO}$ data, available only as 1-hour means from the gas filter correlation measurements, and because the $\mathrm{O}_{3}$ data provide little information about $\mathrm{CH}_{4}$ emission sources.

1. Fiore, A. M. et al. Linking ozone pollution and climate change: The case for controlling methane. Geophys. Res. Lett. 29, 1919, doi:10.1029/2002GL015601 (2002).

2. Prather, M. J., Holmes, C. D. \& Hsu, J. Reactive greenhouse gas scenarios: Systematic exploration of uncertainties and the role of atmospheric chemistry. Geophys. Res. Lett. 39, L09803, doi:10.1029/2012GL051440 (2012).

3. Montzka, S. A., Dlugokencky, E. J. \& Butler, J. H. Non- $\mathrm{CO}_{2}$ greenhouse gases and climate change. Nature 476, 43-50, doi:10.1038/nature10322 (2011).

4. Shindell, D. et al. Simultaneously mitigating near-term climate change and improving human health and food security. Science 335, 183-189, doi:10.1126/ science.1210026 (2012).

5. Dlugokencky, E. J. et al. Observational constraints on recent increases in the atmospheric $\mathrm{CH}_{4}$ burden. Geophys. Res. Lett. 36, L18803, doi:10.1029/ 2009GL039780 (2009).

6. Aydin, M. et al. Recent decreases in fossil-fuel emissions of ethane and methane derived from firn air. Nature 476, 198-201 (2011).

7. Kai, F. M., Tyler, S. C., Randerson, J. T. \& Blake, D. R. Reduced methane growth rate explained by decreased Northern Hemisphere microbial sources. Nature 476, 194-197, doi:10.1038/nature10259 (2011).

8. Levin, I. et al. No inter-hemispheric $\delta^{13} \mathrm{CH}_{4}$ trend observed. Nature 486, E3-E4, doi:10.1038/nature11175 (2012).

9. Simpson, I. J. et al. Long-term decline of global atmospheric ethane concentrations and implications for methane. Nature 488, 490-494, doi:10.1038/ nature11342 (2012).

10. Frankenberg, C. et al. Global column-averaged methane mixing ratios from 2003 to 2009 as derived from SCIAMACHY: Trends and variability. J. Geophys. Res. 116, doi:10.1029/2010JD014849 (2011).

11. Beck, V. et al. Methane airborne measurements and comparison to global models during BARCA. J. Geophys. Res. 117, D15310, doi:10.1029/2011JD017345 (2012).

12. Baker, A. K. et al. Estimating the contribution of monsoon-related biogenic production to methane emissions from South Asia using CARIBIC observations. Geophys. Res. Let. 39, L10813, doi:10.1029/2012GL051756 (2012).

13. Nara, H. et al. Onboard measurement system of atmospheric carbon monoxide in the Pacific by voluntary observing ships. Atmos. Meas. Tech. 4, 2495-2507, doi:10.5194/amt-4-2495-2011 (2011).

14. Terao, Y. et al. Interannual variability and trends in atmospheric methane over the western Pacific from 1994 to 2010. J. Geophys. Res. 116, D14303, doi:10.1029/ 2010JD015467 (2011).

15. National Geophysical Data Center. Version 4 DMSP-OLS Nighttime Lights Time Series. http://ngdc.noaa.gov/eog/dmsp/downloadV4composites.html (2013) (Date of access: 05/04/2014).

16. Elvidge, C. D. et al. A fifteen year record of global natural gas flaring derived from satellite data. Energies 2, 595-622, doi:10.3390/en20300595 (2009).

17. Howarth, R. W., Santoro, R. \& Ingraffea, A. Methane and the greenhouse-gas footprint of natural gas from shale formations. Clim. Change 106, 679-690 (2011).
18. European Commission - JRC Joint Research Centre and PBL Netherlands Environmental Assessment Agency. EDGAR - Emission Database for Global Atmospheric Research, v4.2 FT2010. http://edgar.jrc.ec.europa.eu (2013) (Date of access: 22/05/2014)

19. Conway, T. J. \& Steele, L. P. Carbon dioxide and methane in the Arctic atmosphere. J. Atmos. Chem. 9, 81-99 (1989).

20. Schmidt, M., Graul, R., Sartorius, H. \& Levin, I. Carbon dioxide and methane in continental Europe: a climatology, and ${ }^{222}$ Radon-based emission estimates. Tellus 48B, 457-473 (1996).

21. Necki, J. et al. Six-year record of atmospheric carbon dioxide and methane at a high-altitude mountain site in Poland. Tellus 55B, 94-104 (2003).

22. Tohjima, Y. et al. Temporal changes in the emissions of $\mathrm{CH}_{4}$ and $\mathrm{CO}$ from China estimated from $\mathrm{CH}_{4} / \mathrm{CO}_{2}$ and $\mathrm{CO} / \mathrm{CO}_{2}$ correlations observed at Hateruma Island. Atmos. Chem. Phys. 13, 22893-22930, doi:10.5194/acpd-13-22893-2013 (2013).

23. Akagi, S. K. et al. Emission factors for open and domestic biomass burning for use in atmospheric models. Atmos. Chem. Phys. 11, 4039-4072, doi:10.5194/acp-114039-2011 (2011).

24. Ayers, G. P. Comment on regression analysis of air quality data. Atmos. Environ. 35, 2423-2425 (2001)

25. Ryerson, T. B. et al. Emissions lifetimes and ozone formation in power plant plumes. J. Geophys. Res. 103, 22569-22583 (1998).

26. Turnbull, J. C. et al. Assessment of fossil fuel carbon dioxide and other anthropogenic trace gas emissions from airborne measurements over Sacramento, California in spring 2009. Atmos. Chem. Phys. 11, 705-721, doi:10.5194/acp-11-705-2011 (2011).

27. Karion, A. et al. Methane emissions estimate from airborne measurements over a western United States natural gas field. Geophys. Res. Lett. 20, 703-706, dol:10.1029/93GL00753 (2013).

28. Zeng, J. et al. A study of trajectory quality using methane measurements from Hateruma Island. Atmos. Environ. 37, 1911-1919 (2003).

29. National Oceanic and Atmospheric Administration, National Aeronautics and Space Administration, and United States Air Force. U.S. Standard Atmosphere, 1976. US Government Printing Office, Washington, D.C. (1976).

30. National Geophysical Data Center. VIIRS Nightfire, Nighttime Detection and Characterization of Combustion Sources. http://ngdc.noaa.gov/eog/viirs/ download_viirs_fire.html (2013) (Date of access: 05/04/2014).

31. Intergovernmental Panel on Climate Change (IPCC). Climate Change 2013: The Physical Science Basis. Contribution of Working Group I to the Fifth Assessment Report of the Intergovernmental Panel on Climate Change, edited by Stocker et al., 1535 pp., Cambridge University Press, Cambridge, United Kingdom and New York, NY, USA, doi:10.1017/CBO9781107415324 (2013).

32. Global Methane Initiative. Oil and gas systems. https://www.globalmethane.org/ oil-gas/index.aspx (2004) (Date of access: 05/04/2014).

33. Nara, H. et al. Effect of air composition $\left(\mathrm{N}_{2}, \mathrm{O}_{2}, \mathrm{Ar}\right.$, and $\left.\mathrm{H}_{2} \mathrm{O}\right)$ on $\mathrm{CO}_{2}$ and $\mathrm{CH}_{4}$ measurement by wavelength-scanned cavity ring-down spectroscopy: calibration and measurement strategy. Atmos. Meas. Tech. 5, 2689-2701, doi:10.5194/amt-5 2689-2012 (2012)

\section{Acknowledgments}

We thank the Toyofuji Shipping Co., Ltd. and Kagoshima Senpaku Kaisha, Ltd. for their generous cooperation and participation in the NIES-VOS program, and S. Kariya and T. Yamada of the Global Environmental Forum for their assistance with data collection. We also thank C. Elvidge (NOAA/NGDC) and Y. Morino and T. Nagashima (NIES) for valuable discussion. DMSP data collected by US Air Force Weather Agency, and data processing was made by NOAA's National Geophysical Data Center. Funding was mainly provided by the Global Environment Research Account for National Institutes by the Ministry of the Environment, Japan.

\section{Author contributions}

H.N. and H.T. took the main role in the study design and the data analyses. Y.T. actively participated in the analyses and discussion, H.M. and Y.N. took the leading role in the operation of the monitoring project, T.M. took the key role in the assurance of data quality. All authors participated in the discussion of results and H.N., H.T. and Y.T. wrote the manuscript.

\section{Additional information}

Competing financial interests: The authors declare no competing financial interests.

How to cite this article: Nara, H. et al. Emissions of methane from offshore oil and gas platforms in Southeast Asia. Sci. Rep. 4, 6503; DOI:10.1038/srep06503 (2014).

This work is licensed under a Creative Commons Attribution 4.0 International License. The images or other third party material in this article are included in the article's Creative Commons license, unless indicated otherwise in the credit line; if the material is not included under the Creative Commons license, users will need to obtain permission from the license holder in order to reproduce the material. To view a copy of this license, visit http://creativecommons.org/licenses/by/4.0/ 